\title{
Abordagem reflexiva do Desenvolvimento do Amapá no Período de 1988 a 2018
}

\author{
Edilena e Moura Mendonça \\ Universidade Estadual do Ceará - UECE \\ Prof. Dr. Vico Denis Sousa de Melo \\ Universidade Estadual do Ceará - UECE
}

https://revistas.uece.br/index.php/inovacaotecnologiasocial/article/view/4764

\begin{abstract}
Resumo
O estudo realizado na temática política pública, intitulada como: "Abordagem Reflexiva do Desenvolvimento do Amapá no Período de 1988 a 2018: Trinta Anos de Estado" apresenta a realidade de um Estado após a emancipação e elevação a categoria de unidade federada do Brasil, com levantamento de dados que apontam o grau de evolução conquistado nesse período, objetivando entender a condição de subdesenvolvimento, considerando todas as potencialidades dos recursos naturais e projetos de investimento, bem como a busca da compreensão que levou ao desequilíbrio das contas públicas fragilizando a economia e ampliando as desigualdades sociais. 0 método dialético foi utilizado numa perspectiva de busca de dados quantitativos para servir de base para qualificar a análise reflexiva da abordagem, tendo como fontes obras literárias, indicadores socioeconômicos de órgãos e oficiais, documentos e relatórios do Governo do Estado do Amapá, por meio da Secretaria de Estado da Fazenda e da Secretaria de Estado do Planejamento. Os teóricos abordados, entre outros, são: Gil (2008); Oliveira (2004); Teixeira (2005); Vergara (2005); Lima (2019); Vidal et al (2019); Santiago (2015); Beaud (2004); Weber (2006); Campos (2018). Os resultados demonstram a necessidade de reestruturação administrativa do Governo para reorganização e execução das políticas públicas com maior eficiência e consciência nos gastos públicos.
\end{abstract}

Palavra-chave desenvolvimento socioeconômico; políticas públicas; potencialidades regionais.

\author{
Abstract \\ This study, whose theme is "Reflexive Approach on the Development of Amapá from 1988 \\ to 2018: Thirty Years as a State", presents the reality of the State after its emancipation and \\ uprising as a Federal Unit of Brazil; with a data collection that indicates the level of evolution \\ which has been conquered within this period of time, aiming to understand its \\ underdevelopment condition, considering all natural resources potentialities and \\ investment projects, as well as the search for comprehension of what has taken the Public \\ Accounts to such an instable reality, weakening its economy and broadening its social \\ inequality. The dialectic method has been used as a way of gathering quantitative data in \\ order to serve as basis to qualify the reflexive analysis of this line of action, possessing as \\ sources literary works, socioeconomic indicators from official public agencies, documents
}


and reports about the Amapá Government through the Finance Secretary of the State and also from the Planning Secretary of the State. The authors who have been studied were: Gil (2008); Oliveira (2004); Teixeira (2005); Vergara (2005); Lima (2019); Vidal et al (2019); Santiago (2015); Beaud (2004); Weber (2006); Campos (2018), among others. The results show the necessity of an administrative restructuration in the Government as to reorganize the execution of the public policies in a more efficient and conscious way, regarding the public spending.

Key-word socioeconomic development; public policies; regional potentialities.

\section{Introdução}

A presente pesquisa registra um Amapá com reconhecida riqueza natural fazendo parte de um contexto territorial privilegiado e com um grande potencial socioeconômico, mas com características de Estado subdesenvolvido.

Foi realizada análise reflexiva do processo evolutivo ocorrido no Estado no pósterritório, a partir do desenrolar histórico da formação dessa sociedade reportando-se desde a colonização, considerando a luta pela conquista das ricas terras que formam o Amapá e que foi palco de conflitos entre países que desejavam a exploração da região.

Objetivamente, pretendeu-se com a pesquisa apresentar dados, com a possibilidade de reflexão acerca do cenário envolvido, com a intenção de fornecer subsídios para a projeção de novas políticas públicas que estabeleçam melhoria de vida a população do Amapá.

\section{Campo metodológico: percurso investigado}

A pesquisa surgiu da percepção e inquietação em tentar identificar às razões pelas quais o Amapá ainda é considerado um Estado subdesenvolvido, apesar de todo o potencial de recursos naturais e projetos para região, considerando sua localização e estrutura. A pesquisa também demanda da vivência no setor público, junto a Secretaria de Estado da Fazenda, acompanhando de perto das dificuldades financeiras do Estado, considerando o alto grau de endividamento, dificuldades de novos investimentos, deficiência no equilíbrio das contas públicas.

Como resultado dessa ineficiência, o Estado acumulada grandes dívidas com fornecedores, servidores, previdência social, precatórios, dívidas públicas, que inviabilizam projetos de recuperação socioeconômica o desenvolvimento e qualidade de vida dos amapaenses.

A investigação utilizou o método dialético como meio interpretativo da realidade objetiva do Estado. Nesse método, de acordo com Gil, 2008, p. 13, fundamenta por meio do princípio quantidade e qualidade, onde descreve:

São características imanentes a todos os objetivos e fenômenos e estão inter-relacionados. No processo de desenvolvimento, as mudanças quantitativas graduais geram mudanças qualitativas e essa transformação opera-se por saldos.

Desse modo, a perspectiva metodológica quantitativa serviu de base para a busca de dados qualitativos, permitindo, antes de qualquer coisa, "em maior grau e profundidade, a interpretação das particularidades dos comportamentos ou atitudes dos indivíduos" (OLIVEIRA, 2004, p. 117). A base construtiva para um enfoque crítico-dialético é para 
demonstrar os cenários evolutivos a que se embasou. 0 método dialético pressupõe um contínuo construir e desconstruir de ideias considerando que "o mundo é o conjunto de todos os processos, onde tudo sofre uma transformação concentrada e progressiva. Este encadeamento não é circular, mas espiral" (OLIVEIRA, 2004, p.69), visto que o objeto de estudo estar atrelado a um cotidiano, social, político, administrativo e econômico, o que denota uma visão do social "[...] como um mundo de significados, passível de investigação e a linguagem dos atores sociais e suas práticas as matérias-primas dessa abordagem [...]" (TEIXEIRA, 2005, p.140), pois, exigiu, por parte da investigadora, uma postura crítica fundamentada, já que esteve em contato direto com o ambiente pesquisado, envolvendo-se no fenômeno social concreto.

No âmbito do nivelamento da investigação foi desenvolvido o caráter descritivo com a utilização de técnicas padronizadas de coleta de dados. A pesquisa terá como assento documentos oficiais históricos, obras literárias, referenciais de indicativos sócioeconômico-financeiro, extraídos de sites oficiais, órgãos Estaduais e Federais, como: Secretária de Estado da Fazenda - SEFAZ, Secretaria de Estado do Planejamento - SEPLAN, Atlas do Desenvolvimento Humano no Brasil, Instituto Brasileiro de Geografia e Estatística e outros. Nesse caso os dados recolhidos foram em forma de palavras, gráficos, planilhas e imagens, exigindo grande capacidade de observação por parte da pesquisadora. que demanda uma postura dinâmica diante dos fenômenos observados.

A pesquisa se propôs a refletir sobre os aspectos sociais e econômicos, apresentando um panorama do processo de crescimento evolutivo ocorrido entre os anos de 1988 a 2018, com base no apanhado histórico conceitual até o cenário vivenciado atualmente.

Dentre os procedimento e etapas da pesquisa, a investigadora determinou os objetivos traçados para análise reflexiva, delineando o enfoque do subdesenvolvimento do Estado, considerando as potencialidades para o desenvolvimento. Buscou-se também o traçado conceitual de terminologias para a teorização das abordagens, bem como a seleção das amostras de dados extraídos de documentos oficiais para suporte do relatório, mediante a análise e interpretação dos resultados.

Torna-se oportuno revelar os aspectos singulares, de um ambiente em desenvolvimento com características particulares, favorecendo uma análise e reflexão, a partir de questões de ampla dimensão no que se refere ao real crescimento de um Estado que tem muitas potencialidades e condições de proporcionar a população melhor qualidade de vida.

\section{Análise reflexiva do desenvolvimento do Estado do Amapá}

O cenário amapaense percorrido durante esses trinta anos em que sua emancipação foi anunciada, demanda de um modelo de formação do Amapá que se caracteriza pelo contexto histórico da sua formação como referência darealidade atual. Os conflitos históricos existentes apontam para uma região com proteção fragilizada, mas com grande potencial natural, como parte de uma riqueza reconhecida internacionalmente, motivo de lutas.

O processo de colonização não foi tarefa fácil. Na mais longínqua região, onde o acesso à civilização decorria de investidas de expedições para adentrar uma área desconhecida, tornando-se desafio aos que aventuravam essa jornada. Diante de tantas lutas com bravura, chegada a ora do reconhecimento do solo brasileiro, isto é, a repatriação definitiva, e que a partir de então passou a ser gerida com outras perspectivas. A população crescia, e junto crescia as necessidades locais de sobrevivência.

As pequenas vilas cresciam na medida em que novas conquistas se alcançavam. A ideia e necessidade de povoamento aliada à necessidade de proteção de fronteira fizeram do Amapá um cenário de comando militar. Prova disso, foi à construção da Base Militar erguida na cidade de Amapá para dar suporte aos aliados, em apoio a Segunda Guerra Mundial. Outro ponto de defesa foi à construção do Forte da Fortaleza São José de Macapá, 
erguida para defender as terras brasileiras de invasão inimigas, embora, de fato, nunca tenha sido usado para esse fim.

Longe do centro do governo do Grão Pará, o Amapá era região esquecida e desprovida de recursos que pudessem montar uma infraestrutura capaz de proporcionar independência a região. 0 resultado disso era miséria e inúmeros conflitos, principalmente depois de descoberto grandes áreas para exploração do ouro e madeira, onde atraía pessoas na esperança de encontrar um "punhado" dessa riqueza.

Após anos de abandono, finalmente, novos ares começam a surgir. A transformação do Amapá em Território trouxe esperança de mudanças, um porvir diferente, que pudesse modificar a vida da população. Assim em 13/09/1943 nasce o Território Federal do Amapá. No entanto, os acontecimentos não foi exatamente o que se esperava em termos de desenvolvimento. Algumas modificações após a criação do Território foram feitas, como: transferência da Capital para a cidade de Macapá, criação de novos municípios, indicação para governadores e prefeitos, montagem de uma pequena estrutura administrativa para a governança, recebimento direto de recursos limitados para aplicação nas políticas públicas programadas, construção de escolas, e hospital, energia e água encanada, etc.

Mas o que de fato importava para o Território, era a necessidade, além de atendimento as questões básicas da população, era que desde essa época, já se pensasse em desenvolvimento econômico com autonomia de geração de renda e de recursos próprios. Os incentivos que aqui chegaram não foram suficientes para atendimento em longo prazo. As raras empresas que se instalaram, fizeram tão somente, o extremante básico para que pudessem operacionalizar seus interesses de exploração e enriquecimento. Tanto que no término de seus contratos, a população das regiões em que estavam permaneceram na mesma miséria, com os mesmos problemas de saneamento básico, saúde em estado precário, elevado nível de pobreza, alto índice de violência, exploração sexual acentuada (adulta e infantil), desemprego, educação deficitária, desqualificação profissional, falta de oportunidade de emprego, pois a carência do setor secundário é altíssima ainda hoje. Sem contar da falta de estrutura para atendimento do setor primário, que pelas características da região, deveria ser uma das melhores do país, pois tem grande extensão de terras férteis, mas que precisa ser tratada para produção. 0 que restou foi o setor terciário onde a empregabilidade de serviço e comércio demanda em mais de $80 \%$, principalmente no serviço público, inclusive nos dias atuais.

Enquanto estava na condição de Território ficou sobre a tutela do Governo Federal, com total dependência (financeira e política) para o seu desenvolvimento. Os governadores eram escolhidos por indicação, de acordo com os interesses de seus indicadores (presidentes da República, políticos e grandes empresários). Dentre os governadores (maioria de outros Estados) que passaram pelo território percebe-se na descrição de cada um dos gestores da época que vinham para realizar o essencial, ou tão pouco atender interesses de grupos políticos para se perpetuarem no poder e deixar em segundo plano os interesses da população. Pouco se fez para desabrochar uma região com tantas possibilidades de geração de negócios que pudesse hoje acender uma capacidade de recursos próprios suficientes para as manutenções primárias do governo. Muito pelo contrário, essa dependência persiste até hoje, pois o Estado do Amapá aguarda mensalmente o Fundo de Participação dos Estados - FPE, verba constitucional, para gerir suas políticas públicas.

Em 1988 chega à vez do Amapá dar mais um passo para a autonomia, a elevação em Estado, pois agora faz parte da unidade federada do Brasil, com posição de destaque em área de fronteira, com grandes possibilidades de mercado internacional, com elevação da balança comercial favorável com maior fluxo de exportação, mais oportunidade para o desenvolvimento do setor primário, principalmente para atendimento do mercado interno, diminuindo a importação, mais recursos financeiros - pois mesmo na condição de Estado, o Governo Federal tutelou o Amapá por mais dez anos após a elevação, até 1998 - mas probabilidades de desenvolvimento com infraestruturas básicas e atrativas para o turismo, instalação de indústrias para geração de produtos para abastecimento interno e externo, 
girando mercadorias para aumentar a arrecadação própria, novos empregos, novos mercados, mais produção para elevação do PIB, melhor IDH, mais qualidade de vida. A partir de agora, a escolha direta de seus governantes, tanto na esfera executiva quanto legislativa, em nível federal, estadual e municipal, gerou esperança de eleger representantes que olhasse as potencialidades do Estado e buscasse esse desenvolvimento. Triste engano. Tudo ficou no mesmo. Alguns poucos investimentos, mas com crescimento demográfico aparente e real, principalmente em detrimento do êxodo rural, pois devido as necessidades a esperança era encontrar algo na área urbana para sobreviver. Setor rural, desassistido, a população não se encontra em situação pior por conta as verbas recebidas pelas prefeituras que geram poucos serviços e emprego, mas o fomento a economia se encontra na condição engessada pela limitação das ações públicas.

$\mathrm{Na}$ esfera política o giro de grupos políticos denotando uma oligarquia, se faz presente até os dias atuais, com revezamento de grupos e partidos políticos no poder transforma o Amapá em palco de luta de poderes. E a população? Bem, depois pensam a respeito.

Ao longo desses anos, o que essa oligarquia deixou para o Estado foi uma continua de triste realidade, conhecida desde a sua colonização. 0 serviço público sucateado em todos os níveis. Na saúde, trinte realidade de todo o Brasil, com reflexo no Amapá, hospitais sem remédios, sem leitos, infraestrutura precária, falta de profissionais da saúde. Na educação, escolas deterioradas, problemas no recebimento de verbas, com atrasos constantes nos pagamentos de merenda, transporte e manutenção, professores desmotivados, falta-lhes condições de trabalho e segurança. Na segurança, altos índices de violência, insegurança da população, fortificação do crime organizado. O Estado é desprovido de condições adequado para a exploração do turismo urbano e ecológico que seria seu forte por conta das belíssimas paisagensnaturais aqui encontradas, ruas em péssimas condições e falta constante de manutenção, falta de esgotamento sanitário, carência de energia elétrica, tanto na capital quando nos municípios, que são reflexos dessa realidade.

Todos esses problemas acarretam dificuldade à população, isto é, amento da demanda na capital, traduzindo um impacto social negativo. Com o crescimento desordenado a partir do ano 2000, percebe-se um aumento na escassez de serviços públicos, principalmente na área básicas, uma vez que não houve investimento suficiente de expansão e infraestrutura nessas áreas, tanto é que os municípios, por exemplo, ainda hoje não comportam a demanda na saúde por falta de hospitais especializados de alto padrão que tenham condições de atendimento adequado de acordo com a patologia de cada caso, que muito embora se receba verbas para aplicação em saúde, ainda é precário o atendimento na rede pública do Amapá. 0 Estado dispõe de apenas um hospital de pronto atendimento, e dois de especialidades, o Hospital das Clínicas para adultos e o Hospital da Criança para as crianças e adolescentes. Conta também com um Hospital Maternidade.

No que diz respeito às finanças públicas a realidade é desanimadora. 0 Estado do Amapá é potencialmente rico em recursos naturais, possui a maior área de reserva ambiental do Brasil preservada, - Parque Nacional Montanhas do Tumucumaque ${ }^{1}$ - com um solo rico em minerais, com posição geográfica em de destaque para a internacionalização de mercado. Porém com tudo isso, a realidade do povo amapaense é bem diferente. Os dados alcançados com a pesquisa apresentam contraponto com o efeito dessa realidade. Foi palco de grandes disputas internacionais pelo domínio da região, lutou pela independência e emancipação, no entanto, continua lutando pela sobrevivência com um alto grau de endividamento e dependência financeira (pois depende de cerca de $70 \%$ dos recursos financeiros recebidos da União). De acordo com os dados levantados na SEFAZ/AP, o orçamento para o exercício de 2018 era de $\mathrm{R} \$ 6.175$ bilhões de reais, porém, identificamos as seguintes dívidas consolidas para final do exercício de 2018:

\footnotetext{
1 Localizada no Estado do Amapá e parte do Pará, possui uma área de $38.464 \mathrm{~km}^{2}$, é o maior parque nacional do Brasil e o maior parque de floresta tropical do mundo.
} 
a) De precatório na ordem de $\mathrm{R} \$ 206$ milhões em 2018;

b) Restos a pagar inscritos nos últimos cinco anos incluindo o ano de 2018 na ordem de $\mathrm{R} \$ 1.258$ bilhão;

c) Resto a pagar processados de 2018 foi de $\mathrm{R} \$ 152.750$ milhões;

d) Resto a pagar não processados de 2018 importa em $\mathrm{R} \$ 289.397$ milhões;

e) Dívida fundada total é na ordem de $\mathrm{R} \$ 3.634$ bilhões de reais

Desde o inicio deste século o Brasil vem passando por crises econômicas de grande repercussão, e como unidade federada, o Estado sente todo esse reflexo, como já dito anteriormente, pela dependência do FPE, naturalmente reflete nos valores recebidos. Muito embora, de acordo com a tabela 05 (quadro demonstrativo da receita do Estado do Amapá - 1994-2018), demonstre uma elevação da Receita Total do Estado a cada ano, no entanto, não está sendo suficiente para gerir todos os compromissos, considerando a Dívida Fundada apurada em 2018.

Essa dívida, acumulada por anos, pois é passada de governo a governo, e cada vez aumentando mais, porém nos deixa um questionamento: 0 que aconteceu para o Amapá chegar nesse nível de endividamento a ponto de comprometer seu desenvolvimento?

Como parte integrante do governo, a pesquisadora arrisca em apontar algumas falhas no processo de gestão, com base no pensamento de Queiroz, 2012, p. 37 que diz:

\begin{abstract}
Não se concebe a execução do plano e dos orçamentos como instrumentos de gestão estratégica; não são feitas análises e avaliações das políticas; não se trabalha com prioridades; e não se buscam a integração e a convergência das ações. Por isso, não se enxergou a necessidade de organizar o planejamento governamental, como determinava a Constituição.
\end{abstract}

Queiroz (2012) titula os problemas de gestão como "falhas de governo", e denota como as principais dificuldades existentes para os países em desenvolvimento e consequentemente para o "avanço na qualidade de sua política pública". Em concordância com o autordescrevemos as seguintes falhas: a) decisões temporais - nesta fase o autor reporta-se aos conflitos de interesses de curto prazo dos políticos com os interesses da sociedade que são de longo prazo, ou seja, quando o objetivo de se efetivar um determinado serviço público de qualidade e par isso se fizer necessário aumento da tarifa para arrecadação da receita em período eleitoral for suprido pela vontade política para ganhar vantagem junto aos eleitores; b) falhas de integração entre as programações das esferas de governo - nessa falha o autor aponta que não há integração entre as esferas de governo para resolver problemas que são inerentes as suas esferas, como a mortalidade infantil, que deveria receber a atenção de todas as esferas para juntos resolverem e minimizar essa deficiência, com alinhamento adequado entre si; c) conflito entre a sustentabilidade econômico-ambiental futura e o presente imediato - essa falha diz respeito à dimensão temporal das decisões com transferência negativa do impacto para as futuras gerações em médio e longo prazos, Isto é, são as decisões oportunistas com benefícios instantâneos ou aparente, porém com um auto custo desproporcional, muitas vezes mediante a empréstimos a taxas com juros altos e sem retorno econômico/social que o justifique, onerando o ente público e comprometendo receitas desnecessariamente; d) superposição de ações governamentais - essa falha, segundo o autor é "uma das maiores responsáveis pelo desperdício de recursos públicos em países em desenvolvimento", não há integração entre os programas de governos e as esferas governamentais, muitas vezes desenvolvem ações iguais com o mesmo objetivo, porém de forma individualizada, não conversam, para unirem os programas numa única ação, evitando o desperdício de recursos; e) falta de foco nas programações - essa falha identifica a dificuldade dos gestores políticos em priorizar problemas conforme a demanda, considerando os recursos escassos e acertar na decisão de identificar as reais necessidades prioritárias, muitas vezes, abrindo mão de um programa 
ou ação em detrimento de outro; f) conflito de representatividade nas decisões de alocação de recursos setoriais - essa falha acontece quando a maioria dos gestores públicos responsáveis é representante político de territórios ou de um grupo especifico priorizando setores, comunidades, municípios ou estados em detrimento de outros que tenham o mesmo grau de importância, mas fazem diferenças para atender interesses particulares em vez de público; g) Uso inapropriado de critérios políticos em certas escolhas- essa falha demanda de grande prejuízo a sociedade, pois é utilizado critérios inadequados a preenchimento de cargos ou funções na administração pública em geral para as escolhas dos profissionais que irão ocupara a vaga, ou seja, não atendem o critério profissional com qualificação especifica para o desenvolvimento da função, tornando-se tão somente "cabide de emprego" para garantia eleitoral de grupos políticos; h) atendimento a interesses ilegítimos - para o autor, o "maior problema existente nos Estados de democracia recente", isto é, o cidadão tem a difícil tarefa de induzir seus representantes políticos a não agirem de forma ilegítima, buscando interesses particulares acima aos da sociedade, como fazer "aliança com outros agentes públicos ou grupos de interesses particulares", essa falha induz ao processo de corrupção do "toma lá, dá cá"; i) desvio das funções essenciais de Estado essa falha aborda a execução de políticas públicas desnecessária em detrimento das prioridades em decorrência da "fragilidade técnico-institucional do Estado", isto é, gestores públicos tomam decisões arbitrárias e ineficientes com escolhas inadequadas à sociedade; j) conflito entre racionalidade e compromisso nas decisões -essa falha é descrita pelo autor como sendo decisões de gestores que tendem a tomar decisões sem atender o critério da racionalidade objetiva, mas atender promessas de campanha, não relaciona o custobenefício com base nas prioridades sociais; i) Conflito entre os interesses de órgãos do governo e os interesses da sociedade- essa falha denota que os agentes públicos e as instituições dos países em desenvolvimento, e consequentemente dos estados, tomam empréstimos financeiros em nome da sociedade porém, os bens ou serviços chega em pequena parte aos beneficiário, a parte mais significativa fica no órgão para atendimento de interesses políticos que não social.

Em se tratando do Estado do Amapá e diante de toda a conjuntura política que sempre o permeou, a pesquisadora arrisca em afirmar que todas essas "falhas de governo" se aplicam ao Amapá. Em qualquer segmento público se observa uma falha dessas, em maior ou menor grau.

0 reflexo dessas falhas éinerente a problemática vivenciada pois consistem na incapacidade das instituições e gestores não serem capazes de solidificar o processo de avanço com qualidade das políticas públicas, pois limitam-se a sustentar as decisões de seus interesses.

Como proposta, de forma eficaz na assertiva de que pela educação, com treinamento, qualificação, conscientização e estudos técnicos aprofundadosdo levantamento prioritário do Estado, surjam o interesse imediato dos agentes públicos em geral, desde o técnico, passando pelos gestores de alto escalão até os representantes eleitos de que se o cenário, com base nas falhas apontadas não modificar, caminharemos a passos lentos e o desenvolvimento ficará cada vez mais distante.

Assim, propomos a gestão pública uma reorganização institucional com integração em níveis de esfera e em níveis de poderes para unir esforços em detrimento do desenvolvimento econômico e social que defina as maiores prioridades da sociedade, com maior ataque ao desperdício e sensibilidade no trato à coisa pública.

\section{Considerações finais}

Após anos de luta e conquistas por emancipação e autonomia, o Amapá buscou convergência e articulação para realizar políticas que contribuíssem para o desenvolvimento socioeconômico em suas unidades e poderes.Com base nesse pensamento 
ao longo de décadas criaram-se estratégias para tornar realidade as perspectivas por meio de instituições, projetos, plano e ações para alcançar resultado favorável.

Com esse pensamento o Amapá apresenta duas fases distintas na sua história: o período do Território e o de Estado.

Na condição de Território as principais políticas se voltam à exploração de minérios como fonte natural de recursos, onde se instalaram empresas com o objetivo de explorar a mineração, principalmente o manganês e ouro, e assumiram o compromisso de desenvolver a região central e do entorno com a instalação de infraestrutura básica para a população.

Nesse período sua principal fonte de recurso era as verbas recebidas do Governo Federal que o tinha como principal tutor e definidor de suas políticas públicas. Os recursos que eram destinados ao Território eram para dar base de sustentação às condições mínimas da população que lutava com dificuldades para sobrevivência. Sua base econômica era a agropecuária de subsistência, bem como a exploração da floresta.

As políticas de desenvolvimento para a Amazônia englobavam o Amapá, mas devido sua localização e interesse dos governantes, acomodados pela "paternidade" da União, os projetos e realizações eram mais demorados, prejudicando seu processo evolutivo, pois a população crescia, e junto crescia as necessidades de qualidade vida. Por quase meio século na condição de Território o Amapá pouco desenvolveu políticas que visassem a autonomia econômica que lhe desse sustentabilidade na geração de renda dentro de um plano continuo. Em todos os setores da economia, o que mais se destacou e se destaca ainda hoje é o terceiro setor, principalmente o de serviço e comércio. 0 de serviço ficou caracterizado pela empregabilidade na esfera pública que por muito tempo permeou a geração de renda fortalecendo o comércio com a circulação de mercadorias. No setor secundário, o processo de industrialização sempre foi muito precário, principalmente na indústria de transformação, isto é, quase nada se produzia nesse período, tornando-se dependente do mercado externo. 0 setor primário característico de subsistência não era suficiente para atender a demanda, tendo que importar quase todos os produtos de consumo, assim como os bens de uso e permanente.

Percebe-se que durante o Território o Amapá apresenta um crescimento evolutivo devido o gerenciamento direto dos recursos destinados a sua manutenção. A infraestrutura que conhecemos hoje, principalmente na esfera pública é desse período, como as escolas, hospitais, praças, prédios, tanto que foi a base para a transformação do Estado.

Com a transformação do Amapá em Estado, em termos de infraestrutura pública muito pouco modificou, dando a impressão que o tempo desacelerou. Houve uma ampliação, mas pouco de novo se apresenta. 0 que de fato ocorreu e mais se destaca, foi o crescimento demográfico populacional, com aumento da demanda em todos os serviços públicos, como saúde, educação, infraestrutura, segurança.

Na economia ainda se mantêm como destaque o setor de serviço e comércio, com os maiores índices de giro, o setor secundário e primário continuam na mesma condição do período em que o Amapá era Território.

As problemáticas desse subdesenvolvimento se deram em maior recorrência por questões políticas e administrativas, pois de todos os governantes que passaram pelo Amapá, por menor tempo que fosse, deveriam ter desenvolvido o crescimento socioeconômico de maneira mais concreta, visando independência financeira com a geração de recursos próprios.A condição de dependência dos recursos vindo do FPE é uma característica muito forte ainda nos dias de hoje, pois mais de $70 \%$ das receitas destinadas a manutenção das políticas públicas do Amapá são verbas constitucionais, isto é, menos de $30 \%$ são de recursos gerados com a própria economia, mantendo o grau de dependência.

Embora as políticas públicas que são desenhadas no PPA sejam para desenvolver o Estado, poucos avanços tem se concretizado, pois, ao longo desses trinta anos, pelo volume de recursos, pela capacidade de financiamento de projetos, o Amapá poderia estar em melhores condições.

As crises que são enfrentadas demandam do alto grau de endividamento contraído ao longo de três décadas. Isso interfere diretamente na pretensão de novos investimentos, 
como infraestrutura e saneamento básico, causando reflexo negativo na sociedade, em termos de geração de renda e emprego.

Ao longo dessa dissertação foi demonstrado que a conjuntara em que se apresenta o Estado hoje tem como causa as questões administrativas e de tomada de decisão com definições de prioridades, inclusive em integrar programas e ações em conjunto com a União e os Municípios.

Portanto, entendemos que, para que ocorra de fato o desenvolvimento do Amapá, é necessária uma reorganização na política de gestão, não só no âmbito estadual, mas municipal e federal, pois a integração entre essas esferas poderá apresentar um cenário com coeso nos gastos dos recursos públicos. Lembrando que como base, o fortalecimento das políticas públicas dos municípios, tende a desenvolver melhor o Estado.

\section{Referências bibliográficas}

ANDRADE, Luís. Tópicos de História do Amapá. Macapá: Gráfica São José, 2000.

BEAUD, Michel. História do capitalismo: de 1500 até nossos dias. Tradução Maria Ermantina Galvão Gomes Pereira. São Paulo: Brasiliense, 2004.

BARCELLOS, Annibal. Primeiro passo da Segunda Caminhada. Macapá: Impressa Oficial, 1992.

BOBBIO, Norberto. A teoria das formas de governo na história do pensamento político. Tradução Luiz Sérgio Henriques. São Paulo: EDIPRO, 2017.

BRASIL. Lei No 4.320, de 17 de março de 1964. Acesso, 07/11/2019 - Estatui Normas Gerais de Direito Financeiro para elaboração e controle dos orçamentos e balanços da União, dos Estados, dos Municípios e do Distrito Federal.

BRUNO NETO, Francisco. Constituição Federal - academicamente explicada. São Paulo: Editora Jurídica Brasileira, 2003

FAUSTO, Boris. História do Brasil: cobre um período de mais de quinhentos anos, desde as raízes da colonização portuguesa até nossos dias. São Paulo: Edusp, 1996.

FRIGOTTO, Gaudêncio. Educação e a crise do capitalismo real. São Paulo: Cortez Editora, 1995.

GIL, Antonio Carlos. Métodos e técnicas de pesquisa social. $6^{\text {a }}$ Ed. São Paulo: editora Atlas, 2008.

LIMA, Edyane Silva de. Classes e movimentos sociais: uma perspectiva do serviço social [livro eletrônico]. Curitiba: InterSaberes, 2019. (Série Formação Profissional em Serviço Social)

LINS, Cristóvão. Amazônia: as raízes do atraso. Rio de Janeiro: Daudt Design Editora, 2012.

LINS, Cristóvão. A Jari e a Amazônia. Rio de Janeiro: Dataforma em convênio com a Prefeitura Municipal de Almeirim (PA), 1997.

LOPES, Maria Vilhena. Isto é Amapá. Goiânia: Kelps, 1998. 
NIEDERLE, Paulo André; RADOMSKY, Guilherme Francisco Waterloo. Introdução às teorias do desenvolvimento. Organizadores, coordenado pelo SEAD/UFRGS. Porto Alegre: Editora da UFRGS, 2016.

OLIVEIRA, Dennison de. História do Brasil: política e economia [livro eletrônico]. Curitiba: InterSaberes, 2012. (Série Aspectos da História do Brasil). Livro unip

OLIVEIRA, Silvio Luiz de. Tratado de metodologia científica: projetos de pesquisas, TGI, TCC, monografias, dissertações e teses. São Paulo: Pioneira, 2004.

ROSTOW, Walt Whitman. As etapas do crescimento econômico: um manifesto não comunista. Tradução de Octavio Alves Velho. Rio de Janeiro: Zahar Editores,1960.

SACHS, Ignacy. Desenvolvimento: includente, sustentável, sustentado. Rio de Janeiro: Garamond, 2004.

SANTIAGO, Theo. Do feudalismo ao capitalismo: uma discussão histórica / organização e introdução. 11. Ed. - São Paulo: Contexto, 2015. - (Coleção Textos e Documentos. Livro unip

SANTOS, Fernando Rodrigues dos. História do Amapá. 3ª Ed. Macapá: Gráfica e Editora Valcan Ltda., 1997.

MALLMANN, Loivo José; BALESTRIN, Nádia Luzia; SILVA, Rodolfo dos Santos. Estado e políticas sociais no Brasil: avanços e retrocessos. [livro eletrônico]. Curitiba: InterSaberes, 2017. (Série Metodologia do Serviço Social).

MONTEIRO, Maurílio de Abreu. A ICOMI no Amapá: meio século de exploração mineral. Novos Cadernos NAEA, Belém, v. 6, n. 2, p.113-168, dez. 2003. Disponível em:http://repositorio.ufpa.br/ispui/handle/2011/3158. Acesso em: 05/ago/2019.

SAWAYA, Rubens R...[et all]. Desenvolvimento brasileiro em debate: Grupo de Pesquisa sobre Desenvolvimento Econômico e Política Econômica da Pontifica Universidade Católica de São Paulo (DEPE/PUC-SP) [livro eletrônico]. Antônio Correa de Lacerda (org). São Paulo: Blucher, 2017.

TEIXEIRA, Elizabeth. As três metodologias: acadêmica, da ciência e da pesquisa. Petrópolis: Vozes, 2005.

VERGARA, Sylvia Constant. Métodos de pesquisa em administração. São Paulo: Atlas, 2005.

VIDAL, Ana Carolina. GONDIN, Pollyana Rodrigues. Desenvolvimento capitalista e o serviço social [livro eletrônico]. Curitiba: InterSaberes, 2019. (Série Metodologia do Serviço Social).livrounip

WEBER, Max. A gênese do capitalismo moderno. Organização e comentários Jesse Souza. Tradução Rainer Domschke. São Paulo: Ática, 2006. 